\title{
The gut-microbiota-brain axis in autism: what Drosophila models can offer?
}

\author{
Safa Salim, Ayesha Banu, Amira Alwa, Swetha B. M. Gowda and Farhan Mohammad*i(D)
}

\begin{abstract}
The idea that alterations in gut-microbiome-brain axis (GUMBA)-mediated communication play a crucial role in human brain disorders like autism remains a topic of intensive research in various labs. Gastrointestinal issues are a common comorbidity in patients with autism spectrum disorder (ASD). Although gut microbiome and microbial metabolites have been implicated in the etiology of ASD, the underlying molecular mechanism remains largely unknown. In this review, we have summarized recent findings in human and animal models highlighting the role of the gut-brain axis in ASD. We have discussed genetic and neurobehavioral characteristics of Drosophila as an animal model to study the role of GUMBA in ASD. The utility of Drosophila fruit flies as an amenable genetic tool, combined with axenic and gnotobiotic approaches, and availability of transgenic flies may reveal mechanistic insight into gut-microbiota-brain interactions and the impact of its alteration on behaviors relevant to neurological disorders like ASD.
\end{abstract}

Keywords: Gut-microbiome-brain axis, Autism spectrum disorders, Gastrointestinal issues, Drosophila

\section{Introduction}

The human body hosts $\sim 100$ trillion microbial species on the skin, respiratory tract, genitals, etc. However, the majority of microbial species reside in the gut [1]. The gut microbiome (GM) comprising commensal, symbiotic, and pathogenic microbial communities influences host physiology and pathophysiology such as immunity and metabolism [2]. The GM can respond to stress and brain injuries like traumatic brain injury and ischemia by modulating its composition [3]. The GM interacts with the host system and may affect host homeostasis by affecting nutrient processing, availability, and absorption [1].

The gut-microbiota-brain axis (GUMBA) is a bidirectional communication between the GM and the brain with multiple routes and mechanisms, including neural, endocrine, and immune pathways $[4,5]$. In humans, the neural pathway consists of the vagus nerve that plays

\footnotetext{
* Correspondence: mohammadfarhan@hbku.edu.qa

Division of Biological and Biomedical Sciences (BBS), College of Health \& Life Sciences (CHLS), Hamad Bin Khalifa University (HBKU), Doha 34110, Qatar
}

both afferent and efferent roles in communication between the central nervous system (CNS) and enteric nervous system (ENS) [6, 7]. The GM stimulates the afferent neurons of the ENS, which sends signals to the brain via the vagus nerve that innervates the proximal colon and intestine [8]. The GM can also release neurotransmitters like acetylcholine, gamma-aminobutyric acid, adrenaline, serotonin, dopamine, or neuroactive molecules like short-chain fatty acids (SCFAs) that can induce changes in CNS [8] via the endocrine pathway. The neurotransmitters and neuroactive molecules released by the GM can be grouped under the neuronal pathway considering their pronounced effect on the CNS (Fig. 1). Changes in the gut microbial composition can lead to alteration in levels of metabolites such as SCFAs and lipopolysaccharides. This can compromise the gut metabolism and trigger enhanced immune response and mitochondrial dysfunction, resulting in increased oxidative stress. Sustained oxidative stress can in turn increase intestinal permeability and inflammation, which can exert pro-inflammatory activity and enhance

(c) The Author(s). 2021 Open Access This article is licensed under a Creative Commons Attribution 4.0 International License, which permits use, sharing, adaptation, distribution and reproduction in any medium or format, as long as you give appropriate credit to the original author(s) and the source, provide a link to the Creative Commons licence, and indicate if changes were made. The images or other third party material in this article are included in the article's Creative Commons licence, unless indicated otherwise in a credit line to the material. If material is not included in the article's Creative Commons licence and your intended use is not permitted by statutory regulation or exceeds the permitted use, you will need to obtain permission directly from the copyright holder. To view a copy of this licence, visit http://creativecommons.org/licenses/by/4.0/ The Creative Commons Public Domain Dedication waiver (http://creativecommons.org/publicdomain/zero/1.0/) applies to the data made available in this article, unless otherwise stated in a credit line to the data. 


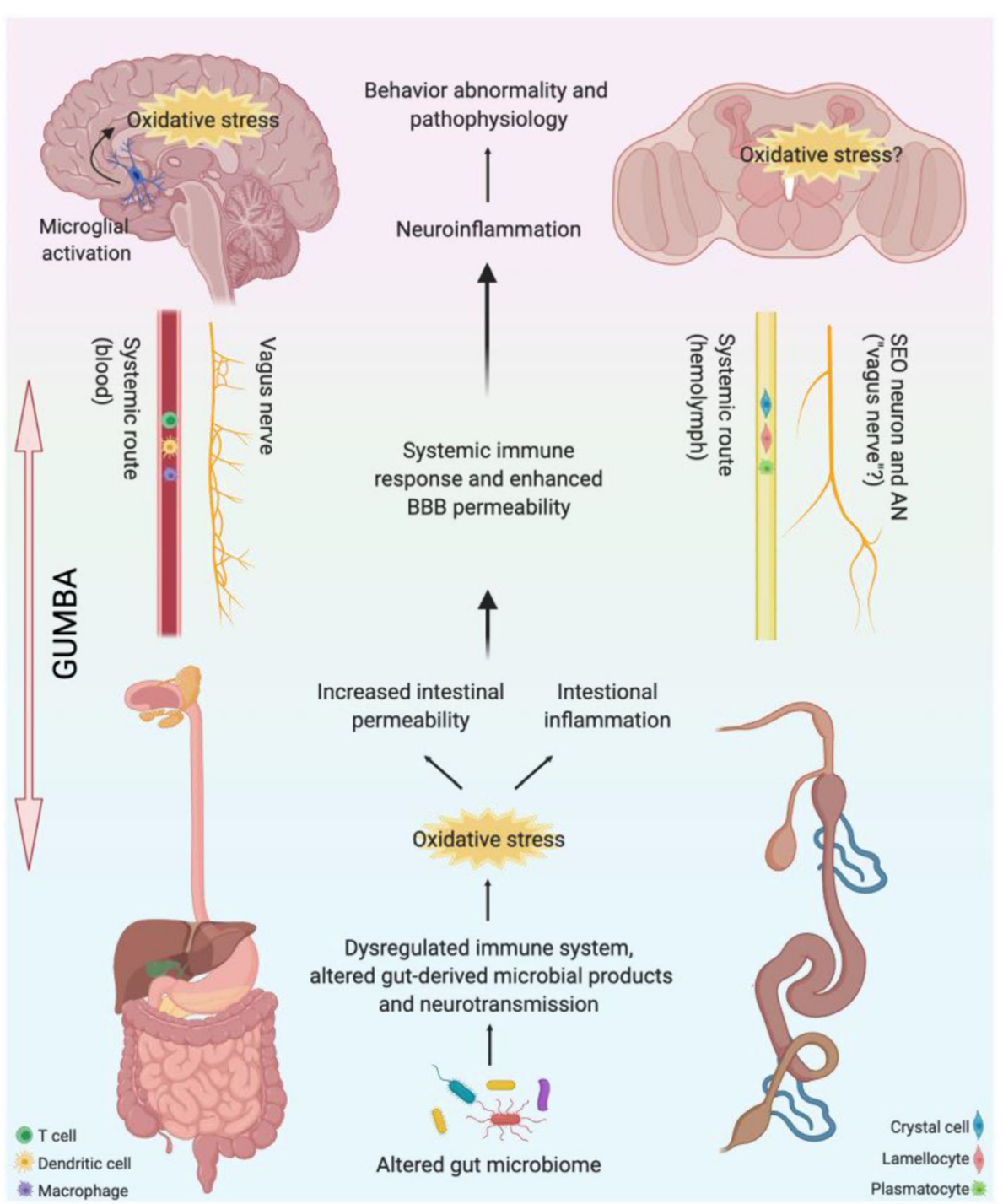

Fig. 1 Illustration of GUMBA in development of neuropathology in humans and fruit flies. Changes in the GM composition and resultant altered gut-derived microbial products and neurotransmission can over-activate the immune system producing increased oxidative stress. Sustained oxidative stress can increase intestinal permeability and inflammation, thus triggering systemic inflammation, which can enhance the blood-brain barrier permeability and cause microglial activation in the brain through the transport of immune cells and metabolites via the systemic route. This would, in turn, enhance oxidative stress and exacerbate neuroinflammation in the brain, resulting in disease pathophysiology and abnormal behavior. Changes in GM composition and its metabolites can also alter vagus nerve signaling and exert effects on the brain and behavior. Many organ systems are homologous between humans and flies; however, the mechanistic basis of GUMBA involvement in neuropathology development remains to be uncovered in flies. SEO, serotonergic output; AN, antennal nerve (Created with BioRender.com)

blood-brain barrier permeability. Microglial activation in the brain can further exacerbate inflammation resulting in malfunction of synapses and manifesting as behavioral abnormalities and neuropathologies [9-14]. Similar to the mammalian system, in Drosophila, altered GM may also result in epithelial oxidative burst causing changes in gut permeability and affecting longevity and behaviors [15-18] (Fig. 1).

Autism spectrum disorder (ASD) is a group of complex developmental disorders clinically characterized by behavioral symptoms, such as impaired communication skills, defective social interaction, and the presence of repetitive behaviors [19]. ASD significantly limits the individual's capacity to live independently, posing a substantial burden on their families. These disorders represent a serious public health concern as their global prevalence has increased with improved detection methods [20]. Although ASD is primarily considered to be a neurodevelopmental disorder, it does not involve only the brain: the gut as well as an interplay between genetic and environmental factors like the microbiome has a crucial role in autism etiology [20-22]. A broad 
range of gastrointestinal (GI) symptoms, such as diarrhea, constipation, abdominal pain, bloating, food allergies, vomiting, gaseousness, and foul-smelling stools, are four times more prevalent in children with ASD in comparison to healthy children [11, 23-25]. However, it remains unclear if defective GUMBA plays a causative role or leads to only comorbidities [26].

The primary support to the hypothesis of GUMBA involvement in ASD comes from various evidence, including gut microbiology, microbial endocrinology, and behavioral studies. A recent study on a rodent autism model constituting maternal obesity and high-fat diet (MHFD) offspring showed that GM dysbiosis mediated the social behavior deficits [27]. Social behavior defects in MHFD mice were restored upon recolonization of microbiota from regular mice in germ-free mice. Moreover, selective recolonization of the mice gut with Lactobacillus reuteri reversed the defects in social behavior [27]. L. reuteri microbial intervention was also recently shown to reverse the social deficits in Cntnap2-/mouse model of ASD by improving the social reward, perhaps through upregulation of metabolites in the tetrahydrobiopterin pathway [28]. These studies provide strong support for the bidirectional communication hypothesis between the gut and the brain in ASD.

While it is known that the composition and diversity of the GM may depend on the host genetic background [29-31], it is unknown whether there is a signature microbiome that is maximally influenced in an ASD background. Furthermore, the molecular mechanism that regulates host-microbiota homeostasis in normal and ASD states is not known. The analyses needed to address this knowledge gap are challenging to perform in humans and rodents due to the high costs and tedious process of comparing the microbiomes of multiple genetic models of ASD.

Drosophila melanogaster can aid in GUMBA research by providing advanced genetic and genomic toolkits to manipulate all cell types in the gut and the brain, along with tractable microbiome systems. At the genetic level, around $65 \%$ of Drosophila genes are similar to human genes, and $75 \%$ of human disease genes have orthologs in fruit flies [32, 33]. Most of these genetic homologs are expressed in Drosophila tissues and perform functions equivalent to those in human tissues [34]. A number of ASD genes have been functionally characterized using Drosophila for their impact on ASD-related behaviors like intellectual disability and social interactions [34-39], thus further establishing Drosophila as a valuable model to study mechanisms underlying human diseases [39]. In a recent study, Chen et al. [36] showed that genetic variation in the protein encoded by one of the autism gene orthologs in Drosophila, lysine demethylase 5 (KDM5), leads to changes in gut physiology, microbiota composition, activation of immune deficiency (IMD) pathway, and social interaction behavior. However, apart from social interaction, whether KDM5 effects on GUMBA also affect other ASD core features remains unclear. Similar to KDM5, many of the evolutionarily conserved ASD genes (Supplementary Table 1) can further be studied in much more detail to describe their effects on the microbiota and ASD-related behaviors. Genetic mutant or cell-specific knockdown of the candidate ASD genes in Drosophila intestine could be used to study whether the Drosophila GM changes in response to genetic backgrounds [36]. The Drosophila system can further be studied to answer if changes in expression of ASD genes in the Drosophila gut leads to microbiome changes causing induction in oxidative stress, and alteration in ASD-related behaviors (Fig. 1).

\section{Increasing prevalence of Gl issues in ASD patients: evidence for altered gut-brain axis}

Among several comorbidities, GI distress in patients with ASD has recently gained attention mainly because of its prevalence and severity [40]. Although there is no direct evidence that GI problems are causative of ASD, multiple studies have suggested that the altered interactions of the GM and the brain might play an important role in ASD physiology. As mentioned earlier, ASD is associated with a range of chronic GI symptoms, including altered bowel habits, abdominal pain, and food intolerance [37]. Gut distress or abdominal discomfort can give rise to behavioral difficulties and potentiate ASD's core stereotypical behaviors, like mouthing gestures, screaming, and self-injury to the abdomen to relieve pain [35]. However, because of communicative defects in ASD patients, GI issues often remain undiagnosed and hence untreated. The prevalence of GI issues in children with ASD is reported to be $23-90 \%$ [38, 41-44]. The risk of malignancy, specifically for colon cancer, also seems to be elevated in affected patients [45]. However, GI issues are more prevalent in those patients that show all the key features of autism rather than just a subset of core features [46], suggesting that GI issues are core features of ASD.

\section{GM is a critical component of the gut-brain axis, but its association with ASD is unclear}

Although the role of GM in relation to human health and disease has been extensively explored over the past decade, its relationship with ASD has only recently attracted attention. Several studies have reported that individuals with ASD and GI issues exhibit an altered gut microbial composition [47-50]. Furthermore, a recent meta-analysis of nine studies involving patients with ASD identified specific microbial species altered in children with ASD, specifically Bifidobacterium, Bacteroides, 
and Lactobacillus species [51, 52]. However, the correlation between patient genetic information and the GM profile has not been thoroughly explored. Interestingly, antibiotic treatment can improve ASD symptoms in some children [53-55]. Although these findings support the idea of the role of the gut and its microbiome in mediating ASD, could it also suggest that ASD individuals are prone to bacterial infections? More studies are required to answer this question. Moreover, several animal model studies have implicated microbiota involvement in models of stress, anxiety, depression, and autism [36, $45,56-58]$. Interestingly, around $60 \%$ of patients with significant mood or affective or psychiatric disorders are thought to have a functional GI disorder [41].

The genetic factors that lead to ASD are not fully understood. ASD is highly heritable [59], but the genetic basis is exceedingly complex, and any single gene that has been associated with ASD accounts for less than 1\% of cases [60]. Multiple studies have identified several hundreds of human genes associated with ASD [61] in scientific efforts to understand the molecular mechanisms underlying ASD worldwide. However, because of high costs, ethical issues, and long animal life cycles, conventional approaches have provided limited insight into the potential functional relevance of these gene candidates or the molecular mechanisms underlying ASD. What is needed is a rapid and effective method to screen conserved gene candidates for functional outcomes and their validation in physiologically relevant mammalian systems.

\section{Drosophila serves as a robust model to study the gut-brain axis and its role in ASD}

Over the last two decades, genome-wide association studies (GWAS) or whole genome or exome sequencing (WGS/WES) have revealed thousands of genetic risk factors associated with various human disorders [62]. However, despite the impressive success rate of finding disease susceptibility loci, the clinical insights derived from these results have been limited, and very few potential loci have successfully been functionally validated $[62,63]$. Hence, the biological context of a large number of identified risk loci remains unclear.

Owing to the vast array of tools for gene manipulation, availability of a large number of insertion or deletion alleles for the majority of fruit fly genes, including homologs of candidate susceptibility genes from GWAS or WES/WGS, and ease of doing experiments with large sample size, Drosophila-based studies have robustly touched almost every human disease biology [63, 64]. Although there are many differences between fruit flies and humans, significant similarities between vertebrates and flies have been demonstrated at the physiological, molecular, and genetic levels [32, 65, 66]. Many vertebrate genes have orthologs expressed in corresponding Drosophila tissues, which perform functions equivalent to those in human tissues [34, 67]. A recent study identified 91 novel ASD-associated genes by analyzing de novo mutation burden in coding regions of candidate genes. Using light-off jump habituation assays in fruit flies, the study functionally characterized the novel genes and found that $40 \%$ of genes showed a defect in suppressing startle response [39]. This indicates that a large proportion of ASD-associated genes have a measurable ASD-related phenotype in Drosophila. Also, apart from learning phenotypes, a few ASD genes have also been shown to regulate Drosophila social behavior by impacting the GM [36].

\section{Drosophila vagus nerve}

In vertebrates, the vagus nerve is a major cranial nerve, which travels from the brain and connects to the intestine. In Drosophila larva, serotonergic output (SEO) neuron leaves CNS via the antennal nerve (AN), analogous to the vertebrate vagus nerve $[68,69]$. The SEO neuron in Drosophila larva innervates central endocrine system median neurosecretory cells (mNSCs) and the ENS and carries sensory information from various body organs like the olfactory ring gland, pharyngeal, and other internal organs, including the intestine $[69,70]$. However, it is unknown whether the serotonergic antennal nerve (AN) sustains the metamorphosis stage and functions in adult flies as the primary "vagus nerve" and innervates the intestine.

\section{Drosophila GM research offers several advantages for analyzing gene-microbiome-brain interactions}

The most direct evidence in establishing a causal relationship between gut-microbiome and ASD that distinguishes it from effect mediated by genetic variants has come from studies in rodents. Different approaches for introducing pre-and post-natal alterations in the microbiome and microbial metabolites perturb various social behaviors associated with neurodevelopmental disorders, including ASD, both in humans and mouse models (reviewed in [71]). For instance, a germ-free humanized mouse model colonized with microbiota from ASD patients promoted ASD-like features, such as decreased communication, increased repetitive behavior, social behavior deficit, and decreased locomotion in an open field $[28,72]$.

Genetically or environmentally manipulated rodent models of autism have furthered our understanding of molecular mechanisms through which microbial dysbiosis in ASD affects animal behaviors [73]. Using known mouse models of ASD (e.g., MHFD), researchers can apply top-down approaches to study if the ASD model possesses microbial dysbiosis and if the altered 
microbiome contributes to the behavioral deficit. Bottom-up approaches (germ-free, gnotobiotic, antibiotic, and probiotics) allow researchers to study the GM's immunological, physiological, and behavioral aspects [73].

Compared to the high level of diversity in the mammalian gut ( $>500$ taxa), Drosophila has a simple microbiome comprising only 5-30 taxa [52, 74]. The Drosophila microbiome is most frequently associated with Lactobacillus, Acetobacter, Enterococcaceae, and to a lesser extent with Wolbachia [51, 75]. Drosophila microbiome affects gut physiology and homeostasis, including gene expression, metabolism [76], anxietyrelated behavior, sleep [77], and social behavior [36, 78].

Microbiome research in Drosophila is aided by advanced genetic and genomic toolkits and tractable microbiome systems (Fig. 2). It is cost-effective and straightforward to generate germ-free Drosophila [77] which, if required, can be maintained as a vigorous culture over multiple generations. Furthermore, germ-free Drosophila can be re-conventionalized with a standardized microbiota to study the role of specific microorganisms. Drosophila presents a repertoire of behaviors and many of these could be used to study core features of autism, like anxiety [79], social interactions [80], and light-pulse habituation [81] (Fig. 2). Autism-related genes and microbiome may have an impact on other body organs and may lead to comorbidities, such as GI issues [36], physical or craniofacial abnormalities [82], epilepsy [83], and other learning disabilities [84], which can also be studied in Drosophila using robust assays (Fig. 2).

Given that key components of conserved signaling pathways like Notch, Hedgehog, Wnt, and epidermal growth factor receptor (EGFR) were identified using Drosophila wings models [85-91], Drosophila wing

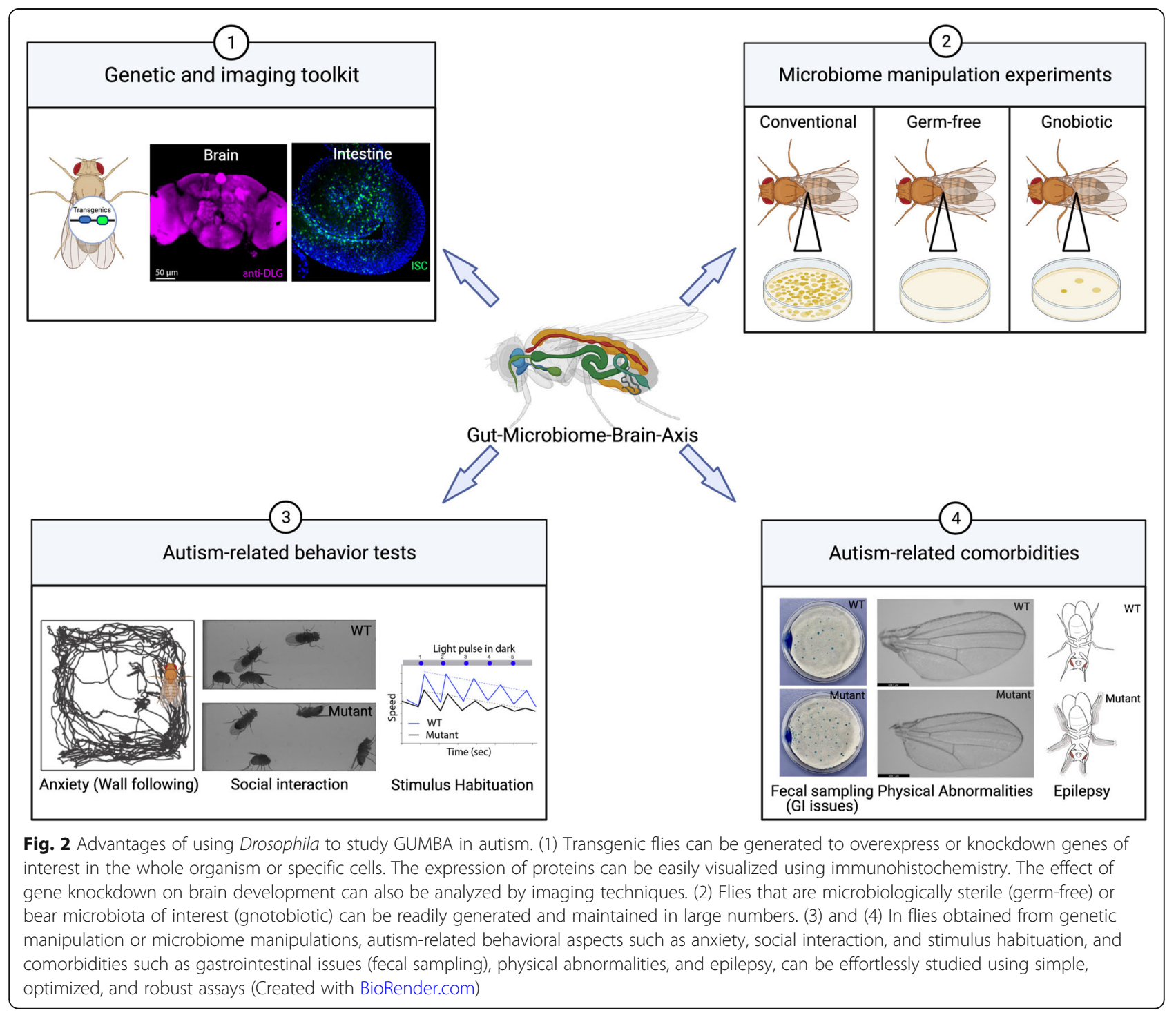


provides an effective system to evaluate the role of autism and other neurodevelopment-related genes in identifying a signaling pathway that could be affected during development [92]. Interestingly, changes in GM by antibiotic treatment or enrichment of Wolbachia can induce morphological changes in the Drosophila wing [93, 94].

\section{The Drosophila gut shares a similar structure to the mammalian gut}

The Drosophila gut is subdivided into the foregut, midgut, and hindgut, which broadly represent the esophagus, small intestine, and large intestine in mammals (Fig. 2). The Drosophila gut is composed of an epithelial layer surrounded by visceral muscles, nerves, and the trachea (Fig. 2). In mammals, intestinal epithelium is separated from the external environment by a mucus membrane. However, in Drosophila, intestinal epithelium is separated from the external environment by a peritrophic membrane, along with a thin mucus layer (Fig. 2D, E) [95].

The Drosophila intestinal epithelial layer is a complex tissue composed of various cell types and performs diverse functions, including digestion, hormone secretion and nutrient absorption. The intestinal epithelium is broadly made up of two types of differentiated cells: enterocytes (ECs) and enteroendocrine (EE) cells, as well as a small percentage of pluripotent intestinal stem cells (ISCs) and enteroblasts (EBs).

The ECs secrete digestive enzymes and absorb nutrients, whereas the EE cells secrete hormones and regulate gut motility. Similar to mammals, the Drosophila intestine is a highly regenerative organ. The epithelial layer is renewed every 5-10 days through proliferation and differentiation of pluripotent ISCs to maintain homeostasis and regeneration. To maintain homeostasis, ISCs proliferate and give rise to a transient progenitor, the EB [equivalent to mammalian Transiently Amplifying (TA) cells]. In mammals, the gut epithelial layer comprises ECs and EEs (tuft, goblet, and paneth cells) confined to the villus, and ISCs and TAs are confined to crypts. Similar to the mammalian mucous layer, the Drosophila gut inner wall is further enveloped by a chitinous layer known as the peritrophic membrane, which serves as a protective barrier between the gut lumen and epithelial cells. The microbiota in the gut interacts with gut proteins, and changes in mucus membrane function may alter the microbial composition. The microbiota can interact with proteins in the peritrophic membrane and mucus membrane, in this way, can modify membrane's properties to allow the passage of microbiota or derived metabolites through the epithelial wall (Fig. 3).

\section{ISC stem cell physiology is governed by conserved molecular mechanisms in Drosophila and mammals}

Recent single-cell RNA sequencing (scRNA-Seq) analysis of mammalian and Drosophila intestines identified evolutionarily conserved gene signatures of gut cell types [97]. Using these signature genes and cluster analyses, several new cell types in the Drosophila intestine have been identified or proposed (Fig. 4). The molecular pathways largely governing the stem cell homeostasis in the gut are well conserved from Drosophila to humans. Molecular pathways regulating stem cell homeostasis in the gut are largely conserved throughout evolution, albeit with minor differences in ISC self-renewal and differentiation into TAs. In contrast, TA differentiation into ECs and EE cells follows a similar lineage system in mammals and Drosophila (Fig. 4) and is governed by similar molecular mechanisms with few differences. For example, Notch, Wnt, and BMP signaling determine the fate of proliferating cells in both Drosophila and mammals $[98,99]$. Similarly, type II neuroblasts (NBs) in the Drosophila brain produce intermediate amplifying cells that closely resemble mammalian neural stem cells (NSCs) [100].

In mammals, paneth and TA cells are specifically found in specialized structures known as crypts. In the Drosophila intestine, which lacks crypts, proliferating stem cells are mainly confined to the midgut [101, 102]. Drosophila EEs are like mammalian EEs, tuft, and goblet cells [97]. Tuft cells are chemosensory, and Drosophila EEs (subpopulation of NPF, DH31 expressing cells) express gustatory chemosensory receptors [103]. Drosophila cardia cells (also known as secretory cells) are like mammalian goblet cells, consistent with their role in secreting mucins. The cardia cells in Drosophila synthesize and secrete the peritrophic membrane [103]. These cells are present in the proventriculus (PV) and express the enzyme O-glycosyltransferase (Pgant4). Drosophila enzyme Pgant4 is most like the mammalian ppGalNAcT10, an abundant enzyme in the digestive system and regulates mucin secretion via mucin-type $\mathrm{O}$ glycosylation [104]. The mammalian paneth cells are like Drosophila aEC2 and aEC3 (subsets of EC), consistent with their role in secreting lysozymes (which function in defense against bacteria) in both cell types [97] (Fig. 4).

Although Drosophila NBs and ISCs originate from distinct germ layers, pupal ISCs and Type I NBs share many similarities, e.g., both ISCs and type I NBs express delta (Dl) relative to their neighboring cells [105]. Moreover, several neural progenitor-specific transcription factors also regulate ISC maintenance and differentiation [106]. These studies suggest that similar molecular mechanisms might regulate ISC and NSC proliferation and differentiation. Therefore using Drosophila as a 


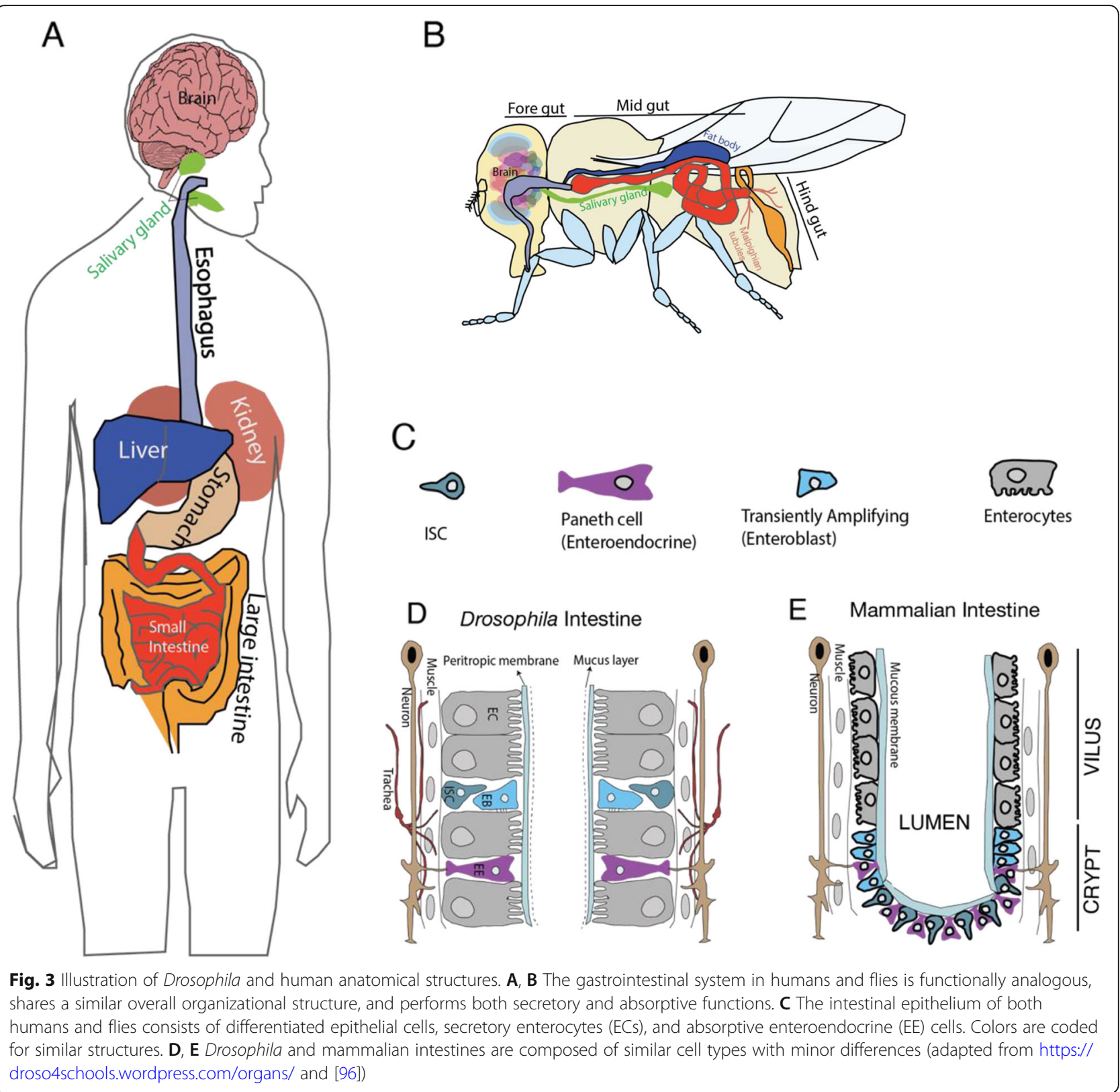

model to study gut or brain development, physiology and plasticity in relation to GUMBA is a good strategy.

\section{Many ASD-associated genes are highly conserved in Drosophila and are expressed in both the gut and the brain}

Drosophila shares a high degree of genetic homology with mammals and exhibits conceptually analogous physiological and pathological mechanisms to higher organisms [66, 67]. Drosophila is often used to study the molecular mechanisms regulating gut homeostasis, plasticity, and behavior [107]. The Drosophila gut expresses many of the same proteins as the human gut [108]. We analyzed the expression enrichment score of high confidence category 1 ASD genes (https://gene.sfari.org/ about-gene-scoring/). Each of these category 1 genes has been implicated in ASD and typically possesses at least three de novo likely gene-disrupting mutations [61].

Out of 207 high confidence autism-related genes, 203 (98\%) were found to have an ortholog in fruit flies (Supplementary File). For 12 high confidence ASD genes (ALDH5A1, CACNA2D3, CSDE1, CSNK2A1, DYNC1H1, HDLBP, MED13, PSMD12, SMARCC2, SPAST, STXBP1, WDFY3), Drosophila had a perfect ortholog DIOPT score (orthology score was determined via flybase.org with 1 representing perfect orthology), 


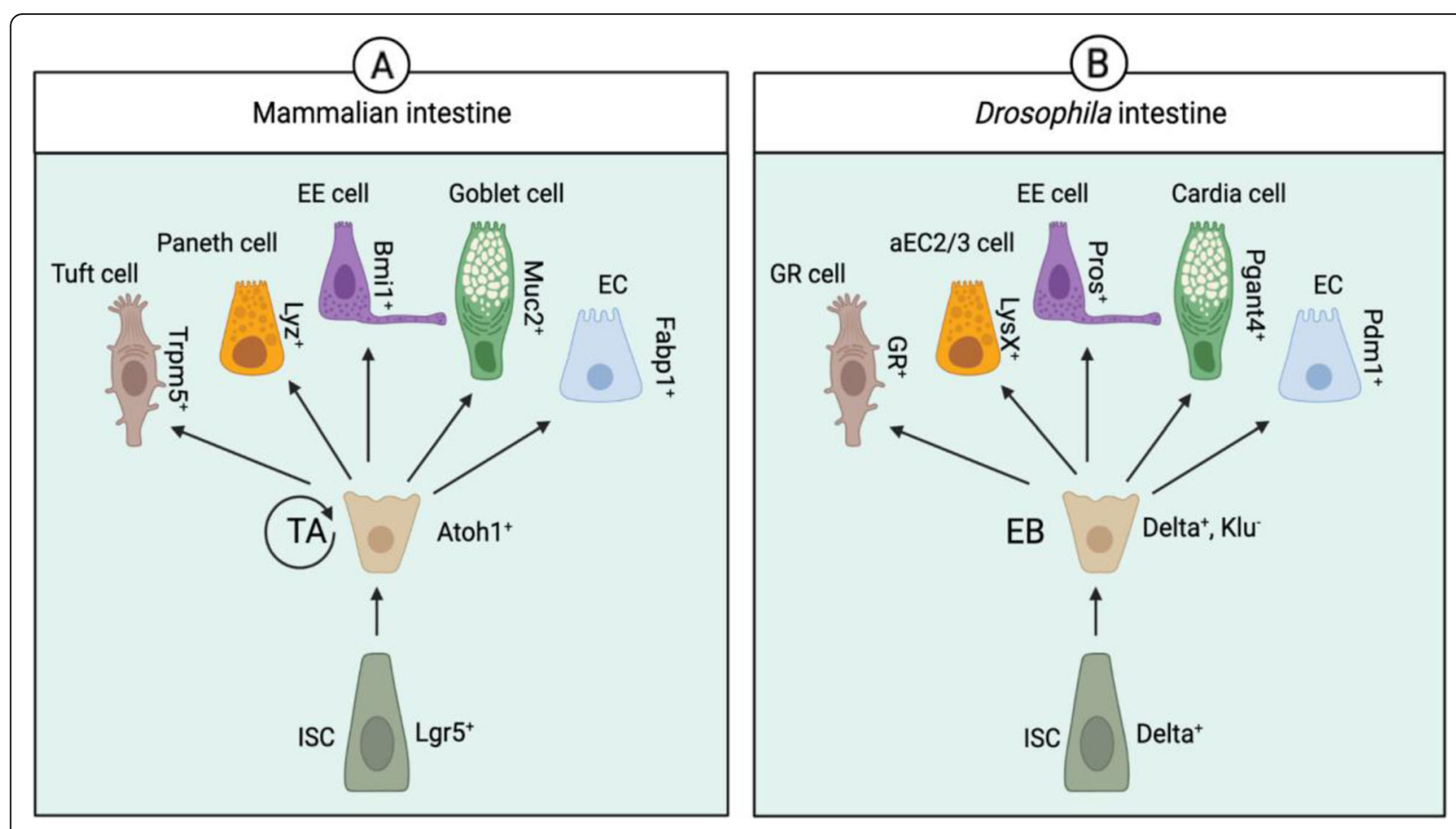

Fig. 4 Schematic depicting cells of intestinal lineages in humans and Drosophila. The pathways of stem cell maintenance and differentiation are largely conserved between Drosophila and mammals with minor differences. Gut plasticity and homeostasis are maintained by regeneration of the gut epithelium. Intestinal stem cells (ISCS) divide asymmetrically to form transient amplifying (TA) cells in humans and enteroblasts (EB) in Drosophila, which differentiates to ECs and EEs. The ECs and EEs cells in the mammalian gut can further be divided into goblet cell (secrets mucous), paneth cell (secrets lysozymes), and tuft cell (expresses chemosensory receptors). In the Drosophila intestine, cardia cells produce mucus layer (analogous to mammalian goblet cell), aEC2/3 cells release lysozyme (analogous to mammalian paneth cell), and gustatory receptorexpressing cells in proventriculus (PV) are analogous to mammalian tuft cells. Intestinal cell types and their markers in mammalian and Drosophila intestines are shown (only one marker for each cell type has been shown). Trmp5 (Transient Receptor Potential Cation Channel Subfamily M Member 5), Lyz (Lysozyme), Enteroendocrine (EE), Bmi1 (B lymphoma Mo-MLV insertion region 1 homolog), Muc2 (Mucin 2), Enterocyte (EC), Fabp1 (Fatty Acid Binding Protein 1), TA (Transiently Amplifying), Atoh1 (Atonal BHLH Transcription Factor 1), ISC (Intestinal Stem Cell), Lgr5 (Leurich repeat-containing G protein-coupled receptor 5), GR (Gustatory Receptor), LysX (Lysozyme X), Pros (Prospero), Pgant4 (Polypeptide NAcetylgalactosaminyltransferase 4), Pdm1 (POU domain protein 1), and Klu (Klumpfuss). Schematics are to show diversity in intestinal cell types and to highlight similarities between mammalian and Drosophila model systems; neither shape, size, nor color has depicted the real cells

while 141 genes had orthology score of $\geq 0.6$ (confirmed by nine out of 15 databases), suggesting that ASDrelated mechanisms involving these high confidence ortholog genes can be studied in Drosophila with high confidence. Fly transgenics expressing cDNA of human autism genes are also available from stock centers for 37 human ASD-related genes (Table 1). These transgenic lines can directly be used to prepare humanized Drosophila autism models or could be used in combination with corresponding fly gene mutants to rescue ASDrelated phenotype and to test the functional effect of an ASD-linked genetic variant in those genes.

Most of the identified genetic mutations (frameshift, nonsense, and splice-site) associated with ASD have mainly been related to the loss-of-function of the affected genes [163, 164]; missense mutations are more likely to have gain-of-function effects [165]. However, the impact of missense mutations mediated gain-offunction has recently been identified. For example,
Pinggera et al. identified and validated a missense mutation V401L (valine to leucine at residue 401) as a gainof-function mutation in one of the autism risk genes, CACNA1D [166], which may explain psychiatric and epileptic phenotypes observed in patients with this mutation. Similarly, gain-of-function missense mutation A636T (alanine to threonine amino acid replacement at residue 636 ) in Glutamate Ionotropic Receptor AMPA Type Subunit 1 (GRIA1) leads to a constitutively active channel [167] and may be linked to some ASD features like intellectual disability (ID), delayed language development and delayed motor development [168]. Similarly, in a Drosophila model of Angelman syndrome (an autism-related disorder), both overexpression and loss of fly UBE3A activity resulted in similar behavioral defects [161] as presumably both genetic knockdown and overexpression resulted in accumulation or too little UBE3A substrate, respectively, which have similar consequences and behavioral effects. Collectively, these studies suggest 
Table 1 List of high confidence orthologs of autism genes (SFARI) [109-162]

\begin{tabular}{|c|c|c|c|}
\hline \multicolumn{4}{|c|}{$\begin{array}{l}\text { List of high confidence orthologs of autism genes (SFARI). The name of human gene, associated fly } \\
\text { ortholog, DIOPT score (out of } 15 \text { databases), and known affected fly behaviors. NA, information not available. }\end{array}$} \\
\hline $\begin{array}{l}\text { Human Gene } \\
\text { Symbol }\end{array}$ & $\begin{array}{l}\text { Drosophila } \\
\text { gene }\end{array}$ & $\begin{array}{l}\text { DIOPT } \\
\text { Score }\end{array}$ & Affected behavior \\
\hline АСТВ & Act5C & 0.73 & Aggression (109) \\
\hline CACNA1A & $\mathrm{cac}$ & 0.60 & Locomotion and courtship (110) \\
\hline CACNA1E & $\mathrm{cac}$ & 0.60 & Locomotion and courtship (110) \\
\hline CASK & CASK & 0.73 & Courtship (111), flight (112), learning (113), memory (114) \\
\hline CSDE1 & Unr & 1.00 & Pain response (115) \\
\hline CSNK2A1 & CkIIalpha & 1.00 & Aggression (116), circadian rhythm (117) \\
\hline CTNNB1 & arm & 0.93 & Locomotion(118), memory (119) \\
\hline DLG4 & dlg1 & 0.80 & Courtship (120), gravitaxis (121), mating and phototaxis (120) \\
\hline DPYSL2 & CRMP & 0.67 & Circadian behavior and memory (122) \\
\hline EBF3 & $\mathrm{kn}$ & 0.93 & Immune response (123) \\
\hline EIF3G & eIF3g2 & 0.93 & Immune response (124) \\
\hline ELAVL3 & fne & 0.67 & Courtship (125), mating (126) \\
\hline GABRB2 & Lcch3 & 0.80 & Aggression (127), male copulation (128), feeding (129) \\
\hline GRIA2 & GluRIA & 0.80 & Sleep $(130,131)$, Long-term memory $(132)$ \\
\hline HNRNPH2 & glo & 0.67 & NA \\
\hline HRAS & Ras85D & 0.87 & NA \\
\hline IRF2BPL & Pits & 0.73 & Locomotion (133) \\
\hline LDB1 & Chi & 0.73 & Posteclosion (134), Locomotion (135) \\
\hline MEIS2 & hth & 0.73 & NA \\
\hline NLGN2 & Nlg3 & 0.67 & Locomotion (136) \\
\hline $\begin{array}{l}\text { N L G N } 3 \text {, } \\
\text { NLGN4X }\end{array}$ & $\mathrm{Nlg} 3$ & 0.80 & Locomotion (136) \\
\hline NRXN1-3 & Nrx-1 & 0.80 & Learning (137), locomotion (138), phototaxis (139) \\
\hline PACS1 & KrT95D & 0.87 & NA \\
\hline PPP1R9B & Spn & 0.60 & Aggression (109), smell perception (140) \\
\hline PTEN & Pten & 0.87 & Locomotion (141), mating (142) \\
\hline PTPN11 & csw & 0.80 & Wing Veins Patterning (143) \\
\hline RFX3 & $\mathrm{Rfx}$ & 0.87 & Smell and taste perception (144) \\
\hline RIMS1 & Rim & 0.67 & NA \\
\hline SCN1A, 2A, $8 \mathrm{~A}$ & para & 0.67 & $\begin{array}{l}\text { Courtship (110), locomotion (145), mating (145), sleep (146), } \\
\text { nociception (147) }\end{array}$ \\
\hline SMARCA2, 4 & brm & 0.87 & Immune response (148) \\
\hline STXBP1 & Rop & 1.00 & NA \\
\hline SYN1 & Syn & 0.73 & $\begin{array}{l}\text { Mating, memory, locomotion, and jump response (149), } \\
\text { learning (150), seizures (151), nociception (152) }\end{array}$ \\
\hline TANC2 & rols & 0.73 & Courtship (153) \\
\hline TBL1XR1 & ebi & 0.93 & NA \\
\hline TCF4 & $\mathrm{da}$ & 0.80 & Memory and negative geotaxis (154) \\
\hline TRIP12 & ctrip & 0.67 & Circadian rhythm (155), locomotor rhythm (156) \\
\hline TSC2 & gig & 0.87 & Flight (157), grooming (158), smell (159) \\
\hline UBE3A & Ube3a & 0.93 & Taste perception (160), climbing, learning, and memory (161) \\
\hline WAC & wcy & 0.73 & Habituation (162), learning (115) \\
\hline ZMYND8 & CG1815 & 0.87 & NA \\
\hline
\end{tabular}

that apart from the loss-of-function studies, more studies are required to gain insight on specific missense mutations causing gain-of-function phenotypes.

The Drosophila model provides a robust system to evaluate both loss- and gain-of-function roles of these human ASD risk genes listed in Table 1. The wild-type human cDNAs could be expressed in either intestine or brain using specific Gal4 drivers. Their either sole impact or rescue effect, combined with fly ortholog mutant, on the microbiome, gut physiology, and plasticity and fly behaviors, can be studied. For many of these genes, Gal4 insertion lines are also available from stock centers. These Gal4 lines are an important resource to delineate neuronal identity or functional neuronal circuits involved in regulating behaviors related to ASD.

Out of the 141 genes with a moderate orthology score of at least $0.6,116(82 \%)$ genes were enriched in the adult brain. Enrichment scores were obtained using Flyatlas2.0, http://flyatlas.gla.ac.uk/FlyAtlas2. We considered a gene to be enriched in a particular tissue if its expression was at least $50 \%$ higher in the tissue than wholebody expression (Supplementary Table 1). Among these 141 genes, 94 genes were enriched in the adult Drosophila brain and gut, 22 were enriched only in the brain, and 78 were more enriched in the gut than in the brain. Among these 78 gut-brain-expressing genes, 11 genes 


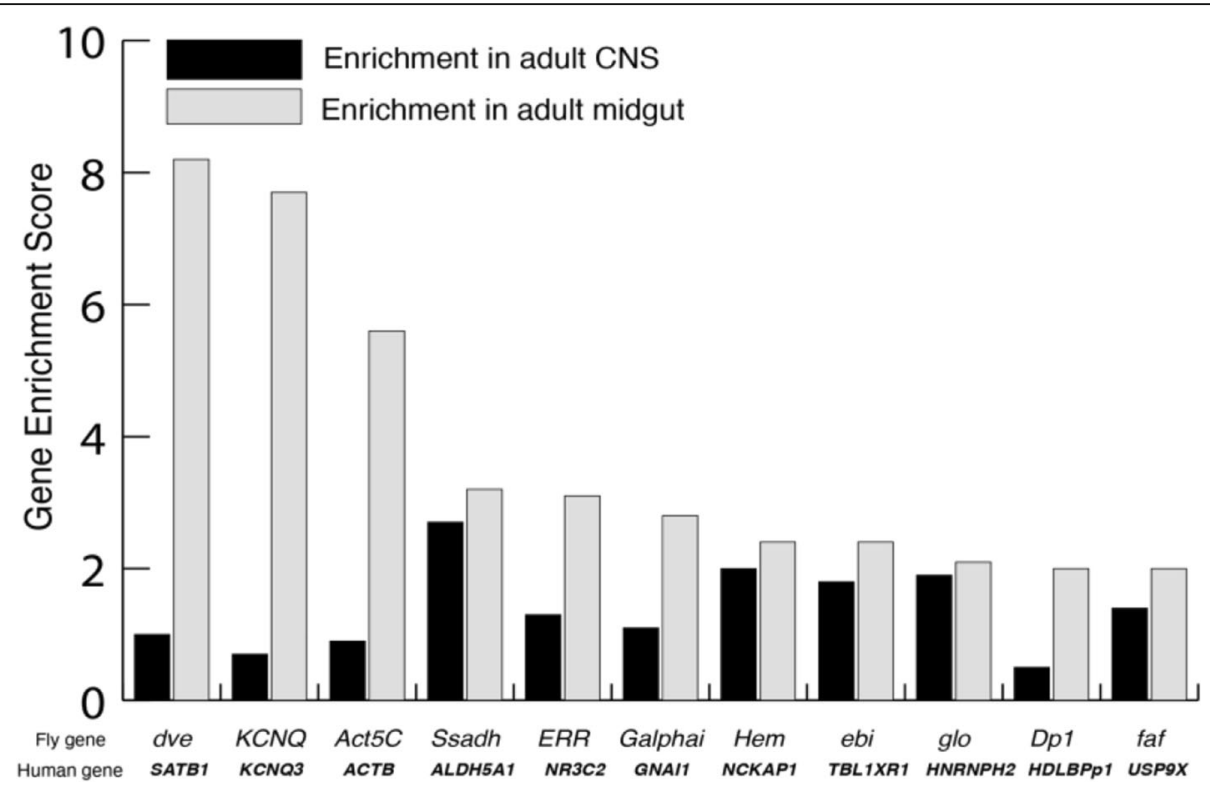

Fig. 5 Top ASD-related genes highly enriched in Drosophila gut. Among genes with moderate orthology score $\geq 0.6,11$ genes have higher expression in the gut than in the brain and enrichment of at least 200\% compared to the whole body. Enrichment scores were obtained from http://flyatlas.gla.ac.uk/FlyAtlas2

were enriched in the gut by $200 \%$ or more (Fig. 5). We propose that these 11 genes are good candidates to study GUMBA in relation to ASD in Drosophila. Among these genes, we did not find any gene that exclusively expresses in the gut.

\section{Limitations of Drosophila GUMBA system}

Although Drosophila genetic tool kits provide access to the advanced reagents required to dissect the role of most human orthologs, not all ASD genes can be modeled in Drosophila since not all ASD genes have an ortholog in Drosophila. Additionally, GM in Drosophila is very simple which limits the studies on complex hostmicrobiota interaction. Although Drosophila can be humanized with human microbiota, Drosophila gut is not suitable for the growth of anaerobic microbiota, which are dominating microorganisms in the human gut. The relevance of Drosophila GM studies to humans is limited to the standard microbiome like Lactobacillus sp., which are common between humans and flies. Furthermore, Drosophila lacks adaptive immunity and has a very simple innate immunity, making it challenging to recapitulate complex changes in the immune system that might take place following GM-mediated changes in ASD pathophysiology.

\section{Conclusion and future directions}

Through animal model-based studies, primarily rodentbased research, our understanding of the effects of the microbiome, its interaction between gut and brain, and its effects on animal physiology and disease pathology has significantly been improved. Given the genetic and neurobehavioral advantages of Drosophila, models of ASD can be generated by studying ASD relevant phenotypes in mutant or in flies with genetically knockdown orthologs of ASD-related genes and their association with the GM, genes showing effects can further be validated by expressing cDNA of human ASD genes. Drosophila lines that are germ-free wild type, overexpressing ASD-related genes, or deficient of ASD-related genes can be exposed to GM from human ASD patients to determine whether the GM regulates ASD-associated behaviors. Apart from core ASD features, Drosophila can also be readily used to study ASD comorbidities or nonneuronal development defects like craniofacial features. Furthermore, highly advanced techniques like optogenetics, live imaging, and neural circuit mapping can be used to gain mechanistic insight and a better understanding of ASD-associated neural circuits and GUMBA components. These approaches will facilitate the identification of better therapeutics for ASD.

\section{Supplementary Information}

The online version contains supplementary material available at https://doi. org/10.1186/s11689-021-09378-x.

Additional file 1: Supplementary Table 1. List of 141 orthologs related to ASD high confidence list with their DIOPT scores.

\section{Acknowledgements}

The authors would like to thank the members of the Farhan lab for their comments. This work received no external funding and was supported by intramural funding to Mohammad Farhan from the College of Health and 
Life Sciences (CHLS), Hamad Bin Khalifa University, Qatar Foundation. Swetha B.M. Gowda and Safa Salim received support from the College of Health and Life Sciences (CHLS), Hamad Bin Khalifa University. All figures were prepared using Biorender and Adobe Illustrator 2020.

\section{Authors' contributions}

Writing, F.M. with contribution from all authors; editing and proofreading, F.M., S.S., A.B., A.A., and S.B.M.G.; visualization, F.M. and S.S.; supervision, F.M. All authors gave final approval for publication. All authors have read and agreed to the published version of the manuscript.

\section{Funding}

This work received no external funding and was supported by intramural funding to Dr. Mohammad Farhan from the College of Health and Life Sciences (CHLS), Hamad Bin Khalifa University, Qatar Foundation. Safa Salim, Ayesha Banu, Amira Alwa, and Swetha B.M. Gowda received support from the College of Health and Life Sciences (CHLS), Hamad Bin Khalifa University. All figures were prepared using Biorender and Adobe Illustrator 2020

\section{Availability of data and materials}

The datasets analyzed during the current study are included in this review.

\section{Declarations}

\section{Ethics approval and consent to participate}

Not applicable

\section{Consent for publication}

Not applicable

\section{Competing interests}

The authors declare that they have no competing interests.

Received: 4 June 2021 Accepted: 6 August 2021

Published online: 15 September 2021

\section{References}

1. Hooper LV, Gordon Jl. Commensal host-bacterial relationships in the gut. Science. 2001:292(5519):1115-8.

2. Pickard JM, Zeng MY, Caruso R, Nunez G. Gut microbiota: role in pathogen colonization, immune responses, and inflammatory disease. Immunol Rev. 2017;279(1):70-89.

3. Rice MW, Pandya JD, Shear DA. Gut microbiota as a therapeutic target to ameliorate the biochemical, neuroanatomical, and behavioral effects of traumatic brain injuries. Front Neurol. 2019;10:875.

4. Schmidt C. Mental health: thinking from the gut. Nature. 2015;518(7540): S12-5. https://doi.org/10.1038/518S13a.

5. Smith PA. The tantalizing links between gut microbes and the brain. Nature. 2015;526(7573):312-4.

6. Cryan JF, Dinan TG. Mind-altering microorganisms: the impact of the gut microbiota on brain and behaviour. Nat Rev Neurosci. 2012;13(10):701-12. https://doi.org/10.1038/nrn3346.

7. Montiel-Castro AJ, Gonzalez-Cervantes RM, Bravo-Ruiseco G, Pacheco-Lopez G. The microbiota-gut-brain axis: neurobehavioral correlates, health and sociality. Front Integr Neurosci. 2013;7:70.

8. Bullich C, Keshavarzian A, Garssen J, Kraneveld A, Perez-Pardo P. Gut vibes in Parkinson's disease: the microbiota-gut-brain axis. Mov Disord Clin Pract. 2019;6(8):639-51.

9. Srikantha P, Mohajeri MH. The possible role of the microbiota-gut-brain-axis in autism spectrum disorder. Int J Mol Sci. 2019;20(9):2115.

10. Fiorentino M, Sapone A, Senger S, Camhi SS, Kadzielski SM, Buie TM, et al. Blood-brain barrier and intestinal epithelial barrier alterations in autism spectrum disorders. Mol Autism. 2016;7:49

11. lovene MR, Bombace F, Maresca R, Sapone A, lardino P, Picardi A, et al. Intestinal dysbiosis and yeast isolation in stool of subjects with autism spectrum disorders. Mycopathologia. 2017;182(3-4):349-63.

12. Madore C, Leyrolle Q, Lacabanne C, Benmamar-Badel A, Joffre C, Nadjar A, et al. Neuroinflammation in autism: plausible role of maternal inflammation, dietary omega 3, and microbiota. Neural Plast. 2016;2016:3597209.
13. Rose S, Bennuri SC, Murray KF, Buie T, Winter H, Frye RE. Mitochondrial dysfunction in the gastrointestinal mucosa of children with autism: a blinded case-control study. PLoS One. 2017;12(10):e0186377.

14. Santocchi E, Guiducci L, Fulceri F, Billeci L, Buzzigoli E, Apicella F, et al. Gut to brain interaction in autism spectrum disorders: a randomized controlled trial on the role of probiotics on clinical, biochemical and neurophysiological parameters. BMC Psychiatry. 2016;16:183.

15. Westfall S, Lomis N, Prakash S. Longevity extension in Drosophila through gut-brain communication. Sci Rep. 2018;8(1):8362.

16. Ha EM, Oh CT, Bae YS, Lee WJ. A direct role for dual oxidase in Drosophila gut immunity. Science. 2005;310(5749):847-50. https://doi.org/10.1126/ science.1117311.

17. Jia Y, Jin S, Hu K, Geng L, Han C, Kang R, et al. Gut microbiome modulates Drosophila aggression through octopamine signaling. Nat Commun. 2021; 12(1):2698. https://doi.org/10.1038/s41467-021-23041-y.

18. Schretter CE, Vielmetter J, Bartos I, Marka Z, Marka S, Argade S, et al. A gut microbial factor modulates locomotor behaviour in Drosophila. Nature. 2018;563(7731):402-6. https://doi.org/10.1038/s41586-018-0634-9.

19. Arlington VA. Diagnostic and statistical manual of mental disorders. 5th ed; 2013.

20. Chiarotti F, Venerosi A. Epidemiology of autism spectrum disorders: a review of worldwide prevalence estimates since 2014. Brain Sci. 2020;10(5):274.

21. Chaste P, Leboyer M. Autism risk factors: genes, environment, and geneenvironment interactions. Dialogues Clin Neurosci. 2012;14(3):281-92.

22. Orefice LL, Zimmerman AL, Chirila AM, Sleboda SJ, Head JP, Ginty DD. Peripheral mechanosensory neuron dysfunction underlies tactile and behavioral deficits in mouse models of ASDs. Cell. 2016;166(2):299-313.

23. Berding K, Donovan SM. Microbiome and nutrition in autism spectrum disorder: current knowledge and research needs. Nutr Rev. 2016;74(12):72336.

24. Fulceri F, Morelli M, Santocchi E, Cena H, Del Bianco T, Narzisi A, et al. Gastrointestinal symptoms and behavioral problems in preschoolers with autism spectrum disorder. Dig Liver Dis. 2016;48(3):248-54.

25. Marler S, Ferguson BJ, Lee EB, Peters B, Williams KC, McDonnell E, et al. Association of rigid-compulsive behavior with functional constipation in autism spectrum disorder. J Autism Dev Disord. 2017:47(6):1673-81. https:// doi.org/10.1007/s10803-017-3084-6.

26. Mayer EA, Padua D, Tillisch K. Altered brain-gut axis in autism: comorbidity or causative mechanisms? Bioessays. 2014;36(10):933-9. https://doi.org/10.1 002/bies.201400075.

27. Buffington SA, Di Prisco GV, Auchtung TA, Ajami NJ, Petrosino JF, Costa-Mattioli M. Microbial reconstitution reverses maternal dietinduced social and synaptic deficits in offspring. Cell. 2016;165(7): 1762-75.

28. Buffington SA, Dooling SW, Sgritta M, Noecker C, Murillo OD, Felice DF, et al. Dissecting the contribution of host genetics and the microbiome in complex behaviors. Cell. 2021;184(7):1740-56 e16.

29. Li H, Jasper H. Gastrointestinal stem cells in health and disease: from flies to humans. Dis Model Mech. 2016;9(5):487-99.

30. Mowat AM, Agace WW. Regional specialization within the intestinal immune system. Nat Rev Immunol. 2014;14(10):667-85.

31. Wang J, Thingholm LB, Skieceviciene J, Rausch P, Kummen M, Hov JR, et al. Genome-wide association analysis identifies variation in vitamin $\mathrm{D}$ receptor and other host factors influencing the gut microbiota. Nat Genet. 2016; 48(11):1396-406.

32. Pandey UB, Nichols CD. Human disease models in Drosophila melanogaster and the role of the fly in therapeutic drug discovery. Pharmacol Rev. 2011; 63(2):411-36.

33. Reiter LT, Potocki L, Chien S, Gribskov M, Bier E. A systematic analysis of human disease-associated gene sequences in Drosophila melanogaster. Genome Res. 2001;11(6):1114-25. https://doi.org/10.1101/gr.169101.

34. Chintapalli VR, Wang J, Dow JA. Using FlyAtlas to identify better Drosophila melanogaster models of human disease. Nat Genet. 2007;39(6):715-20.

35. Chakraborty P, Carpenter KLH, Major S, Deaver M, Vermeer S, Herold B, et al. Gastrointestinal problems are associated with increased repetitive behaviors but not social communication difficulties in young children with autism spectrum disorders. Autism. 2021;25(2):405-15.

36. Chen K, Luan X, Liu Q, Wang J, Chang X, Snijders AM, et al. Drosophila histone demethylase KDM5 regulates social behavior through immune control and gut microbiota maintenance. Cell Host Microbe. 2019;25(4):53752 e8. 
37. Lefter R, Ciobica A, Timofte D, Stanciu C, Trifan A. A descriptive review on the prevalence of gastrointestinal disturbances and their multiple associations in autism spectrum disorder. Medicina (Kaunas). 2019;56(1):11.

38. Nikolov RN, Bearss KE, Lettinga J, Erickson C, Rodowski M, Aman MG, et al. Gastrointestinal symptoms in a sample of children with pervasive developmental disorders. J Autism Dev Disord. 2009:39(3):405-13.

39. Stessman HA, Xiong B, Coe BP, Wang T, Hoekzema K, Fenckova M, et al. Targeted sequencing identifies 91 neurodevelopmental-disorder risk genes with autism and developmental-disability biases. Nat Genet. 2017;49(4):51526.

40. Wasilewska J, Klukowski M. Gastrointestinal symptoms and autism spectrum disorder: links and risks - a possible new overlap syndrome. Pediatric Health Med Ther. 2015;6:153-66.

41. Gorrindo P, Williams KC, Lee EB, Walker LS, McGrew SG, Levitt P. Gastrointestinal dysfunction in autism: parental report, clinical evaluation, and associated factors. Autism Res. 2012;5(2):101-8.

42. Ibrahim SH, Voigt RG, Katusic SK, Weaver AL, Barbaresi WJ. Incidence of gastrointestinal symptoms in children with autism: a population-based study. Pediatrics. 2009;124(2):680-6.

43. Molloy CA, Manning-Courtney P. Prevalence of chronic gastrointestinal symptoms in children with autism and autistic spectrum disorders. Autism. 2003;7(2):165-71.

44. Valicenti-McDermott M, McVicar K, Rapin I, Wershil BK, Cohen H, Shinnar S. Frequency of gastrointestinal symptoms in children with autistic spectrum disorders and association with family history of autoimmune disease. J Dev Behav Pediatr. 2006;27(2 Suppl):S128-36.

45. Drossman DA. The role of psychosocial factors in gastrointestinal illness. Scand J Gastroenterol Suppl. 1996;221:1-4.

46. Wang LW, Tancredi DJ, Thomas DW. The prevalence of gastrointestinal problems in children across the United States with autism spectrum disorders from families with multiple affected members. J Dev Behav Pediatr. 2011;32(5):351-60.

47. Adams JB, Johansen L, Powell LD, Quig D, Rubin RA. Gastrointestinal flora and gastrointestinal status in children with autism--comparisons to typical children and correlation with autism severity. BMC Gastroenterol. 2011;11:22.

48. Hsiao EY, McBride SW, Hsien S, Sharon G, Hyde ER, McCue T, et al. Microbiota modulate behavioral and physiological abnormalities associated with neurodevelopmental disorders. Cell. 2013;155(7):1451-63.

49. Parracho HM, Bingham MO, Gibson GR, McCartney AL. Differences between the gut microflora of children with autistic spectrum disorders and that of healthy children. J Med Microbiol. 2005;54(Pt 10):987-91.

50. Rosenfeld CS. Microbiome disturbances and autism spectrum disorders. Drug Metab Dispos. 2015;43(10):1557-71.

51. Bravo JA, Forsythe P, Chew MV, Escaravage E, Savignac HM, Dinan TG, et al. Ingestion of Lactobacillus strain regulates emotional behavior and central GABA receptor expression in a mouse via the vagus nerve. Proc Natl Acad Sci U S A. 2011;108(38):16050-5. https://doi.org/10.1073/pnas.1102999108.

52. Xu M, Xu X, Li J, Li F. Association between gut microbiota and autism spectrum disorder: a systematic review and meta-analysis. Front Psychiatry. 2019;10:473

53. Kuhn M, Grave S, Bransfield R, Harris S. Long term antibiotic therapy may be an effective treatment for children co-morbid with Lyme disease and autism spectrum disorder. Med Hypotheses. 2012;78(5):606-15.

54. Posey DJ, Kem DL, Swiezy NB, Sweeten TL, Wiegand RE, McDougle CJ. A pilot study of D-cycloserine in subjects with autistic disorder. Am J Psychiatry. 2004;161(11):2115-7.

55. Sandler RH, Finegold SM, Bolte ER, Buchanan CP, Maxwell AP, Vaisanen ML, et al. Short-term benefit from oral vancomycin treatment of regressiveonset autism. J Child Neurol. 2000;15(7):429-35.

56. Bailey MT, Dowd SE, Galley JD, Hufnagle AR, Allen RG, Lyte M. Exposure to a social stressor alters the structure of the intestinal microbiota: implications for stressor-induced immunomodulation. Brain Behav Immun. 2011;25(3): 397-407.

57. O'Mahony SM, Hyland NP, Dinan TG, Cryan JF. Maternal separation as a model of brain-gut axis dysfunction. Psychopharmacology. 2011;214(1):7188. https://doi.org/10.1007/s00213-010-2010-9.

58. Park AJ, Collins J, Blennerhassett PA, Ghia JE, Verdu EF, Bercik P, et al. Altered colonic function and microbiota profile in a mouse model of chronic depression. Neurogastroenterol Motil. 2013;25(9):733-e575.

59. Sandin S, Lichtenstein P, Kuja-Halkola R, Hultman C, Larsson H, Reichenberg A. The heritability of autism spectrum disorder. JAMA. 2017;318(12):1182-4.
60. Hu WW. The expanding genomic landscape of autism: discovering the 'forest' beyond the 'trees'. Future Neurol. 2013;8(1):29-42. https://doi.org/1 $0.2217 /$ fnl.12.83

61. Satterstrom FK, Kosmicki JA, Wang J, Breen MS, De Rubeis S, An JY, et al. Large-scale exome sequencing study implicates both developmental and functional changes in the neurobiology of autism. Cell. 2020;180(3):568-84 e23.

62. Cano-Gamez E, Trynka G. From GWAS to function: using functional genomics to identify the mechanisms underlying complex diseases. Front Genet. 2020;11:424.

63. Kasai Y, Cagan R. Drosophila as a tool for personalized medicine: a primer. Perinat Med. 2010;7(6):621-32. https://doi.org/10.2217/pme.10.65.

64. Wangler MF, Yamamoto S, Bellen HJ. Fruit flies in biomedical research. Genetics. 2015;199(3):639-53.

65. Bokolia NP, Mishra M. Hearing molecules, mechanism and transportation: modeled in Drosophila melanogaster. Dev Neurobiol. 2015;75(2):109-30.

66. Chao HT, Davids M, Burke E, Pappas JG, Rosenfeld JA, McCarty AJ, et al. A syndromic neurodevelopmental disorder caused by de novo variants in EBF3. Am J Hum Genet. 2017;100(1):128-37.

67. Bellen HJ, Yamamoto S. Morgan's legacy: fruit flies and the functional annotation of conserved genes. Cell. 2015:163(1):12-4.

68. Miroschnikow A, Schlegel P, Schoofs A, Hueckesfeld S, Li F, Schneider-Mizell $\mathrm{CM}$, et al. Convergence of monosynaptic and polysynaptic sensory paths onto common motor outputs in a Drosophila feeding connectome. Elife. 2018;7:e40247.

69. Schoofs A, Huckesfeld S, Surendran S, Pankratz MJ. Serotonergic pathways in the Drosophila larval enteric nervous system. J Insect Physiol. 2014;69: $118-25$.

70. Huser A, Rohwedder A, Apostolopoulou AA, Widmann A, Pfitzenmaier JE, Maiolo EM, et al. The serotonergic central nervous system of the Drosophila larva: anatomy and behavioral function. PLoS One. 2012;7(10):e47518.

71. Sharon G, Sampson TR, Geschwind DH, Mazmanian SK. The central nervous system and the gut microbiome. Cell. 2016;167(4):915-32.

72. Sharon G, Cruz NJ, Kang DW, Gandal MJ, Wang B, Kim YM, et al. Human gut microbiota from autism spectrum disorder promote behavioral symptoms in mice. Cell. 2019:177(6):1600-18 e17.

73. Needham BD, Tang W, Wu WL. Searching for the gut microbial contributing factors to social behavior in rodent models of autism spectrum disorder. Dev Neurobiol. 2018;78(5):474-99.

74. Han G, Lee HJ, Jeong SE, Jeon CO, Hyun S. Comparative analysis of Drosophila melanogaster gut microbiota with respect to host strain, sex, and age. Microb Ecol. 2017;74(1):207-16

75. Broderick NA, Lemaitre B. Gut-associated microbes of Drosophila melanogaster. Gut Microbes. 2012;3(4):307-21.

76. Wong AC, Dobson AJ, Douglas AE. Gut microbiota dictates the metabolic response of Drosophila to diet. J Exp Biol. 2014;217(Pt 11):1894-901.

77. Selkrig J, Mohammad F, Ng SH, Chua JY, Tumkaya T, Ho J, et al. The Drosophila microbiome has a limited influence on sleep, activity, and courtship behaviors. Sci Rep. 2018;8(1):10646.

78. Venu I, Durisko Z, Xu J, Dukas R. Social attraction mediated by fruit flies' microbiome. J Exp Biol. 2014;217(Pt 8):1346-52.

79. Mohammad F, Aryal S, Ho J, Stewart JC, Norman NA, Tan TL, et al. Ancient anxiety pathways influence Drosophila defense behaviors. Curr Biol. 2016; 26(7):981-6

80. Sun Y, Qiu R, Li X, Cheng Y, Gao S, Kong F, et al. Social attraction in Drosophila is regulated by the mushroom body and serotonergic system. Nat Commun. 2020;11(1):5350.

81. Fenckova M, Blok LER, Asztalos L, Goodman DP, Cizek P, Singgih EL, et al. Habituation learning is a widely affected mechanism in Drosophila models of intellectual disability and autism spectrum disorders. Biol Psychiatry. 2019; 86(4):294-305.

82. Marcogliese PC, Deal SL, Andrews J, Harnish JM, Bhavana VH, Graves HK, et al. Drosophila functional screening of de novo variants in autism uncovers deleterious variants and facilitates discovery of rare neurodevelopmental diseases. bioRxiv. 2021

83. Mohammad F, Singh P, Sharma A. A Drosophila systems model of pentylenetetrazole induced locomotor plasticity responsive to antiepileptic drugs. BMC Syst Biol. 2009:3(1):11. https://doi.org/10.1186/1752-0509-3-11.

84. Yildizoglu T, Weislogel JM, Mohammad F, Chan ES, Assam PN, Claridge-Chang A. Estimating Information Processing in a Memory System: The Utility of Metaanalytic Methods for Genetics. PLoS Genet. 2015;11(12):e1005718. 
85. Molnar C, Ruiz-Gomez A, Martin M, Rojo-Berciano S, Mayor F, de Celis JF. Role of the Drosophila non-visual ss-arrestin kurtz in hedgehog signalling. PLoS Genet. 2011;7(3):e1001335.

86. Dworkin I, Gibson G. Epidermal growth factor receptor and transforming growth factor-beta signaling contributes to variation for wing shape in Drosophila melanogaster. Genetics. 2006;173(3):1417-31.

87. Testa ND, Dworkin I. The sex-limited effects of mutations in the EGFR and TGF-beta signaling pathways on shape and size sexual dimorphism and allometry in the Drosophila wing. Dev Genes Evol. 2016;226(3):159-71.

88. Yan SJ, Gu Y, Li WX, Fleming RJ. Multiple signaling pathways and a selector protein sequentially regulate Drosophila wing development. Development. 2004;131(2):285-98.

89. Strigini M, Cohen SM. A Hedgehog activity gradient contributes to AP axial patterning of the Drosophila wing. Development. 1997;124(22):4697-705.

90. Diaz de la Loza MC, Thompson BJ. Forces shaping the Drosophila wing. Mech Dev. 2017;144(Pt A):23-32.

91. Bier E. Drosophila, the golden bug, emerges as a tool for human genetics. Nat Rev Genet. 2005;6(1):9-23.

92. Yusuff T, Jensen M, Yennawar S, Pizzo L, Karthikeyan S, Gould DJ, et al. Drosophila models of pathogenic copy-number variant genes show global and non-neuronal defects during development. PLoS Genet. 2020;16(6): e1008792.

93. Kriesner $\mathrm{P}$, Conner WR, Weeks AR, Turelli M, Hoffmann AA. Persistence of a Wolbachia infection frequency cline in Drosophila melanogaster and the possible role of reproductive dormancy. Evolution. 2016;70(5): 979-97.

94. Weiland SO, Detcharoen M, Schlick-Steiner BC, Steiner FM. No influence of antibiotic on locomotion in Drosophila nigrosparsa after recovery, but influence on microbiome, possibly mediating wing-morphology change. bioRxiv. 2021

95. Buchon N, Osman D, David FP, Fang HY, Boquete JP, Deplancke B, et al. Morphological and molecular characterization of adult midgut compartmentalization in Drosophila. Cell Rep. 2013;3(5):1725-38.

96. Miguel-Aliaga I, Jasper $H$, Lemaitre B. Anatomy and physiology of the digestive tract of Drosophila melanogaster. Genetics. 2018;210(2):357-96.

97. Hung RJ, Hu Y, Kirchner R, Liu Y, Xu C, Comjean A, et al. A cell atlas of the adult Drosophila midgut. Proc Natl Acad Sci U S A. 2020;117(3):1514-23.

98. Fre S, Bardin A, Robine S, Louvard D. Notch signaling in intestinal homeostasis across species: the cases of Drosophila, Zebrafish and the mouse. Exp Cell Res. 2011;317(19):2740-7.

99. van Es JH, van Gijn ME, Riccio O, van den Born M, Vooijs M, Begthel H, et al. Notch/gamma-secretase inhibition turns proliferative cells in intestinal crypts and adenomas into goblet cells. Nature. 2005;435(7044):959-63.

100. Merkle FT, Alvarez-Buylla A. Neural stem cells in mammalian development. Curr Opin Cell Biol. 2006;18(6):704-9.

101. Fox DT, Spradling AC. The Drosophila hindgut lacks constitutively active adult stem cells but proliferates in response to tissue damage. Cell Stem Cell. 2009;5(3):290-7.

102. Jiang $H$, Edgar BA. Intestinal stem cells in the adult Drosophila midgut. Exp Cell Res. 2011;317(19):2780-8.

103. Park JH, Kwon JY. Heterogeneous expression of Drosophila gustatory receptors in enteroendocrine cells. PLoS One. 2011;6(12):e29022.

104. Bennett EP, Mandel U, Clausen H, Gerken TA, Fritz TA, Tabak LA. Control of mucin-type O-glycosylation: a classification of the polypeptide GalNActransferase gene family. Glycobiology. 2012;22(6):736-56. https://doi.org/10.1 093/glycob/cwr182.

105. Artavanis-Tsakonas S, Delidakis C, Fehon RG. The Notch locus and the cell biology of neuroblast segregation. Annu Rev Cell Biol. 1991;7(1):427-52. https://doi.org/10.1146/annurev.cb.07.110191.002235.

106. Li Z, Guo X, Huang H, Wang C, Yang F, Zhang Y, et al. A switch in tissue stem cell identity causes neuroendocrine tumors in Drosophila gut. Cell Rep. 2020;30(6):1724-34 e4.

107. Capo F, Wilson A, Di Cara F. The intestine of Drosophila melanogaster: an emerging versatile model system to study intestinal epithelial homeostasis and most-microbial interactions in humans. Microorganisms. 2019;7(9):336.

108. Buchon N, Osman D. All for one and one for all: regionalization of the Drosophila intestine. Insect Biochem Mol Biol. 2015;67:2-8.

109. Edwards AC, Zwarts L, Yamamoto A, Callaerts P, Mackay TF. Mutations in many genes affect aggressive behavior in Drosophila melanogaster. BMC Biol. 2009;7:29
110. Peixoto AA, Hall JC. Analysis of temperature-sensitive mutants reveals new genes involved in the courtship song of Drosophila. Genetics. 1998;148(2): 827-38.

111. Slawson JB, Kuklin EA, Ejima A, Mukherjee K, Ostrovsky L, Griffith LC. Central regulation of locomotor behavior of Drosophila melanogaster depends on a CASK isoform containing CaMK-like and L27 domains. Genetics. 2011 . 187(1):171-84.

112. Zordan MA, Massironi M, Ducato MG, Te Kronnie G, Costa R, Reggiani C, et al. Drosophila CAKI/CMG protein, a homolog of human CASK, is essential for regulation of neurotransmitter vesicle release. J Neurophysiol. 2005;94(2): 1074-83.

113. Gillespie JM, Hodge JJ. CASK regulates CaMKII autophosphorylation in neuronal growth, calcium signaling, and learning. Front Mol Neurosci. 2013; $6: 27$.

114. Malik BR, Gillespie JM, Hodge JJ. CASK and CaMKIl function in the mushroom body alpha'/beta' neurons during Drosophila memory formation. Front Neural Circuits. 2013;7:52.

115. Neely GG, Hess A, Costigan M, Keene AC, Goulas S, Langeslag M, et al. A genome-wide Drosophila screen for heat nociception identifies alpha2delta3 as an evolutionarily conserved pain gene. Cell. 2010;143(4): 628-38.

116. Zwarts L, Vulsteke V, Buhl E, Hodge JJL, Callaerts P. SlgA, encoded by the homolog of the human schizophrenia-associated gene PRODH, acts in clock neurons to regulate Drosophila aggression. Dis Model Mech. 2017;10(6): 705-16.

117. Lear BC, Merrill CE, Lin JM, Schroeder A, Zhang L, Allada R. A G proteincoupled receptor, groom-of-PDF, is required for PDF neuron action in circadian behavior. Neuron. 2005:48(2):221-7.

118. Dupont P, Besson MT, Devaux J, Lievens JC. Reducing canonical Wingless/ Wnt signaling pathway confers protection against mutant Huntingtin toxicity in Drosophila. Neurobiol Dis. 2012;47(2):237-47.

119. Tan Y, Yu D, Busto GU, Wilson C, Davis RL. Wnt signaling is required for long-term memory formation. Cell Rep. 2013;4(6):1082-9.

120. Mendoza-Topaz C, Urra F, Barria R, Albornoz V, Ugalde D, Thomas U, et al. DLGS97/SAP97 is developmentally upregulated and is required for complex adult behaviors and synapse morphology and function. J Neurosci. 2008; 28(1):304-14.

121. Armstrong JD, Texada MJ, Munjaal R, Baker DA, Beckingham KM. Gravitaxis in Drosophila melanogaster: a forward genetic screen. Genes Brain Behav. 2006;5(3):222-39.

122. Morris DH, Dubnau J, Park JH, Rawls JM Jr. Divergent functions through alternative splicing: the Drosophila CRMP gene in pyrimidine metabolism, brain, and behavior. Genetics. 2012;191(4):1227-38.

123. Crozatier M, Ubeda JM, Vincent A, Meister M. Cellular immune response to parasitization in Drosophila requires the EBF orthologue collier. PLoS Biol. 2004;2(8):E196.

124. Foley $\mathrm{E}, \mathrm{O}$ 'Farrell PH. Functional dissection of an innate immune response by a genome-wide RNAi screen. PLoS Biol. 2004;2(8):E203.

125. Zanini D, Jallon JM, Rabinow L, Samson ML. Deletion of the Drosophila neuronal gene found in neurons disrupts brain anatomy and male courtship. Genes Brain Behav. 2012;11(7):819-27.

126. Bussell JJ, Yapici N, Zhang SX, Dickson BJ, Vosshall LB. Abdominal-B neurons control Drosophila virgin female receptivity. Curr Biol. 2014:24(14):1584-95.

127. Yuan $Q$, Song $Y$, Yang $C H$, Jan $L Y$, Jan $Y N$. Female contact modulates male aggression via a sexually dimorphic GABAergic circuit in Drosophila. Nat Neurosci. 2014;17(1):81-8.

128. Pavlou HJ, Lin AC, Neville MC, Nojima T, Diao F, Chen BE, et al. Neural circuitry coordinating male copulation. Elife. 2016;5.

129. Cheung SK, Scott K. GABAA receptor-expressing neurons promote consumption in Drosophila melanogaster. PLoS One. 2017;12(3):e0175177.

130. Mazzotta GM, Damulewicz M, Cusumano P. Better sleep at night: how light influences sleep in Drosophila. Front Physiol. 2020;11:997.

131. Zimmerman JE, Chan MT, Lenz OT, Keenan BT, Maislin G, Pack Al. Glutamate Is a Wake-Active Neurotransmitter in Drosophila melanogaster. Sleep. 2017; 40(2)

132. Kacsoh BZ, Barton S, Jiang Y, Zhou N, Mooney SD, Friedberg I, et al. New Drosophila long-term memory genes revealed by assessing computational function prediction methods. G3 (Bethesda). 2019;9(1):251-67.

133. Marcogliese PC, Shashi V, Spillmann RC, Stong N, Rosenfeld JA, Koenig MK, et al. IRF2BPL is associated with neurological phenotypes. Am J Hum Genet. 2018;103(2):245-60. 
134. Hari P, Deshpande M, Sharma N, Rajadhyaksha N, Ramkumar N, Kimura K, et al. Chip is required for posteclosion behavior in Drosophila. J Neurosci. 2008;28(37):9145-50. https://doi.org/10.1523/JNEUROSCI.1882-08.2008.

135. Lavoy S, Chittoor-Vinod VG, Chow CY, Martin I. Genetic modifiers of neurodegeneration in a Drosophila model of Parkinson's disease. Genetics. 2018;209(4):1345-56.

136. Wu J, Tao N, Tian Y, Xing G, Lv H, Han J, et al. Proteolytic maturation of Drosophila Neuroligin 3 by tumor necrosis factor alpha-converting enzyme in the nervous system. Biochim Biophys Acta Gen Subj. 2018;1862(3):440-50.

137. Zeng X, Sun M, Liu L, Chen F, Wei L, Xie W. Neurexin-1 is required for synapse formation and larvae associative learning in Drosophila. FEBS Lett. 2007;581(13):2509-16. https://doi.org/10.1016/j.febslet.2007.04.068.

138. Sun M, Liu L, Zeng X, Xu M, Liu L, Fang M, et al. Genetic interaction between Neurexin and CAKI/CMG is important for synaptic function in Drosophila neuromuscular junction. Neurosci Res. 2009;64(4):362-71.

139. Tian Y, Li T, Sun M, Wan D, Li Q, Li P, et al. Neurexin regulates visual function via mediating retinoid transport to promote rhodopsin maturation. Neuron. 2013;77(2):311-22.

140. Sambandan D, Yamamoto A, Fanara JJ, Mackay TF, Anholt RR. Dynamic genetic interactions determine odor-guided behavior in Drosophila melanogaster. Genetics. 2006;174(3):1349-63.

141. Mensah LB, Davison C, Fan SJ, Morris JF, Goberdhan DC, Wilson C. Finetuning of PI3KJAKT signalling by the tumour suppressor PTEN is required for maintenance of flight muscle function and mitochondrial integrity in ageing adult drosophila melanogaster. PLoS One. 2015;10(11):e0143818.

142. Kuo TH, Fedina TY, Hansen I, Dreisewerd K, Dierick HA, Yew JY, et al. Insulin signaling mediates sexual attractiveness in Drosophila. PLoS Genet. 2012; 8(4):e1002684

143. Oishi K, Gaengel K, Krishnamoorthy S, Kamiya K, Kim IK, Ying H, et al. Transgenic Drosophila models of Noonan syndrome causing PTPN11 gainof-function mutations. Hum Mol Genet. 2006;15(4):543-53.

144. Dubruille R, Laurencon A, Vandaele C, Shishido E, Coulon-Bublex M, Swoboda $P$, et al. Drosophila regulatory factor $X$ is necessary for ciliated sensory neuron differentiation. Development. 2002;129(23):5487-98.

145. Kaas GA, Kasuya J, Lansdon P, Ueda A, lyengar A, Wu CF, et al. Lithiumresponsive seizure-like hyperexcitability is caused by a mutation in the Drosophila voltage-gated sodium channel gene paralytic. eNeuro. 2016;3(5).

146. Petruccelli E, Lansdon P, Kitamoto T. Exaggerated nighttime sleep and defective sleep homeostasis in a Drosophila knock-in model of human epilepsy. PLoS One. 2015;10(9):e0137758.

147. Pittendrigh B, Reenan R, ffrench-Constant RH, Ganetzky B. Point mutations in the Drosophila sodium channel gene para associated with resistance to DDT and pyrethroid insecticides. Mol Gen Genet. 1997;256(6):602-10.

148. He X, Yu J, Wang M, Cheng Y, Han Y, Yang S, et al. Bap180/Baf180 is required to maintain homeostasis of intestinal innate immune response in Drosophila and mice. Nat Microbiol. 2017;2:17056.

149. Godenschwege TA, Reisch D, Diegelmann S, Eberle K, Funk N, Heisenberg $M$, et al. Flies lacking all synapsins are unexpectedly healthy but are impaired in complex behaviour. Eur J Neurosci. 2004:20(3):611-22. https:// doi.org/10.1111/j.1460-9568.2004.03527.x.

150. Michels B, Chen YC, Saumweber T, Mishra D, Tanimoto H, Schmid B, et al. Cellular site and molecular mode of synapsin action in associative learning. Learn Mem. 2011:18(5):332-44.

151. Paemka L, Mahajan VB, Skeie JM, Sowers LP, Ehaideb SN, Gonzalez-Alegre P, et al. PRICKLE1 interaction with SYNAPSIN I reveals a role in autism spectrum disorders. PLoS One. 2013;8(12):e80737. https://doi.org/10.1371/ journal.pone.0080737.

152. Engel GL, Marella S, Kaun KR, Wu J, Adhikari P, Kong EC, et al. Sir2/Sirt1 links acute inebriation to presynaptic changes and the development of alcohol tolerance, preference, and reward. J Neurosci. 2016;36(19):5241-51.

153. Guo H, Bettella E, Marcogliese PC, Zhao R, Andrews JC, Nowakowski TJ, et al. Disruptive mutations in TANC2 define a neurodevelopmental syndrome associated with psychiatric disorders. Nat Commun. 2019;10(1): 4679

154. Tamberg L, Jaago M, Saalik K, Sirp A, Tuvikene J, Shubina A, et al. Daughterless, the Drosophila orthologue of TCF4, is required for associative learning and maintenance of the synaptic proteome. Dis Model Mech. 2020; 13(7).

155. Lamaze A, Lamouroux A, Vias C, Hung HC, Weber F, Rouyer F. The E3 ubiquitin ligase CTRIP controls CLOCK levels and PERIOD oscillations in Drosophila. EMBO Rep. 2011;12(6):549-57.
156. Sathyanarayanan S, Zheng X, Kumar S, Chen CH, Chen D, Hay B, et al. Identification of novel genes involved in light-dependent CRY degradation through a genome-wide RNAi screen. Genes Dev. 2008;22(11):1522-33.

157. Schnorrer F, Schonbauer C, Langer CC, Dietzl G, Novatchkova M, Schernhuber K, et al. Systematic genetic analysis of muscle morphogenesis and function in Drosophila. Nature. 2010;464(7286):287-91.

158. Canal I, Acebes A, Ferrus A. Single neuron mosaics of the drosophila gigas mutant project beyond normal targets and modify behavior. J Neurosci. 1998:18(3):999-1008.

159. Acebes A, Ferrus A. Increasing the number of synapses modifies olfactory perception in Drosophila. J Neurosci. 2001;21(16):6264-73.

160. Zhang YV, Raghuwanshi RP, Shen WL, Montell C. Food experience-induced taste desensitization modulated by the Drosophila TRPL channel. Nat Neurosci. 2013;16(10):1468-76.

161. Wu Y, Bolduc FV, Bell K, Tully T, Fang Y, Sehgal A, et al. A Drosophila model for Angelman syndrome. Proc Natl Acad Sci U S A. 2008;105(34):12399-404.

162. Lugtenberg D, Reijnders MR, Fenckova M, Bijlsma EK, Bernier R, van Bon BW, et al. De novo loss-of-function mutations in WAC cause a recognizable intellectual disability syndrome and learning deficits in Drosophila. Eur J Hum Genet. 2016;24(8):1145-53.

163. Sanders SJ, He X, Willsey AJ, Ercan-Sencicek AG, Samocha KE, Cicek AE, et al. Insights into autism spectrum disorder genomic architecture and biology from 71 risk loci. Neuron. 2015;87(6):1215-33.

164. Stessman HA, Bernier $R$, Eichler EE. A genotype-first approach to defining the subtypes of a complex disease. Cell. 2014;156(5):872-7.

165. Turner TN, Douville C, Kim D, Stenson PD, Cooper DN, Chakravarti A, et al. Proteins linked to autosomal dominant and autosomal recessive disorders harbor characteristic rare missense mutation distribution patterns. Hum Mol Genet. 2015;24(21):5995-6002.

166. Pinggera A, Mackenroth $L$, Rump A, Schallner J, Beleggia F, Wollnik B, et al. New gain-of-function mutation shows CACNA1D as recurrently mutated gene in autism spectrum disorders and epilepsy. Hum Mol Genet. 2017; 26(15):2923-32

167. Zuo J, De Jager PL, Takahashi KA, Jiang W, Linden DJ, Heintz N. Neurodegeneration in Lurcher mice caused by mutation in delta2 glutamate receptor gene. Nature. 1997;388(6644):769-73.

168. Geisheker MR, Heymann G, Wang T, Coe BP, Turner TN, Stessman HAF, et al. Hotspots of missense mutation identify neurodevelopmental disorder genes and functional domains. Nat Neurosci. 2017:20(8):1043-51. https://doi.org/1 $0.1038 / \mathrm{nn} .4589$

\section{Publisher's Note}

Springer Nature remains neutral with regard to jurisdictional claims in published maps and institutional affiliations.

Ready to submit your research? Choose BMC and benefit from:

- fast, convenient online submission

- thorough peer review by experienced researchers in your field

- rapid publication on acceptance

- support for research data, including large and complex data types

- gold Open Access which fosters wider collaboration and increased citations

- maximum visibility for your research: over $100 \mathrm{M}$ website views per year

At $\mathrm{BMC}$, research is always in progress.

Learn more biomedcentral.com/submissions 